\title{
Um dispositivo mínimo para uma violência máxima
}

\author{
Ana Bigotte Vieira
}

Blessed, Meg Stuart /Damaged Goods \& EIRA (Ghent, 2007; espectáculo vencedor do Prémio Francês da Crítica em $2008^{1}$

Entra um homenzinho pequeno e esquisito no palco. Gesticula mecanicamente, com um ar meio conformado, embora pareça profundamente desesperado, revelam as suas feições. Veste-se todo de branco e calça uns chinelinhos de piscina muito ridiculos que the tolhem os passos. Este homem (Francisco Camacho) anda geometricamente entre uma palmeira, um cisne gigante e uma casa, todos em cartão... e assim se faz a sua vida, até que começa a chover.

E chove, chove, chove, chove, chove.... chove torrencialmente e sem tréguas. A chuva não pára e não há quem a faça parar. 0 homem abriga-se em casa e congela: pára completamente, deixamos de o ter como protagonista. 0 seu 'congelamento' deixa-nos a ver a chuva a inundar o quadrado que faz de palco e a molhar tudo, a fazer o cartão ceder. A chuva torna-se o protagonista. Até que, com o tempo, a chuva começa a desfazer a palmeira, que se verga, e o cisne, cujas asas empapam e se recurvam.

Desesperado, o homem tolhido e ainda dentro de casa volta a mexer-se: primeiro um esgar, depois um braço, depois o corpo todo. Num repente levanta-se: agarra numa lata de spraye - já com a palmeira completamente tombada o cisne inteiramente desfeito, o telhado da casa a ameaçar a ruína e água a escorrer pela parede - desenha a grande velocidade na parede uma palmeira e um cisne e vira-se para ela a observar, incapaz de aceitar a ruína do seu mundo. É o mundo antigo que tenta reproduzir nas ruínas desfeitas do que tem agora. Mas esta solução não dura muito porque a chuva continua e este homenzinho está

Ana Bigotte Vieira está a fazer

Doutoramento em Estudos Artísticos com uma bolsa da FCT, sendo Visiting Scholar em Performance Studies na New York University entre 2009 e 2012 irremediavelmente exposto a ela. E nós, enquanto público, expostos à sua tragédia que é também a nossa. A violência da chuva no palco obriga a plateia a sentir-lhe a humidade a atmosfera da sala torna-se húmida, há um desconforto do palco que se propaga para a plateia em jeito de sorriso amargo. E ao mesmo tempo é, os estragos que provoca são irreversiveis. 0 tempo faz a água acumular-se e a vida deste homenzinho desmoronar-se à nossa frente. Somos colocados na posição incómoda de testemunhas.
Fui ver Blessed de Meg Stuart (com Francisco Camacho) no fim de uma semana em que participei em Crisis of Everything Everywhere ${ }^{2}$, um seminário de reflexão sobre os novos movimentos sociais (Tahir Square, Grécia, Occupy Wall Street/OWS...) e os problemas que Ihes estão subjacentes (a crise da divida, a desagregação do estado social, a financeirização da vida quotidiana). Este Seminário foi organizado pelo Beaver Group, uma plataforma que nasceu há dez anos, fruto do Independent Study Program do Whitney Museum, um dos mais conceituados cursos independentes de curadoria. Situado no no 16 da Beaver Street, perto de Wall Street, 16 Beaver é um espaço dirigido por artistas e define-se como uma plataforma permanente de apresentação, discussão e produção crítica de projectos artísticos, políticos, económicos e culturais. As suas actividades, muito embora inseridas no 'mundo da arte' pautam-se por serem sobretudo 'discursivas'. Como se, num mundo onde o pensamento crítico é muito reduzido, abrir espaço para o seu exercício fosse tarefa urgente $^{3}$, talvez a mais importante de todas - mais importante mesmo do que a definição de 'artístico' ou as questões da autoria ou 'obra' artística.

Em Crisis of Everything Everywhere, organizei juntamente com Sandra Lang um dia de acção/reflexão sobre 'corpo' e 'espaço' neste tipo de protestos. Interessavanos abordar questões de 'presença' e de 'representação' (questões comuns ao que se passa em palco), de acção política e de tipo de protesto, do que podem os corpos em conjunto no espaço da rua fazer para mudar o rumo das coisas; de como se organizam e do que nos dizem os seus corpos sobre estes modos de organização. Eis algumas das nossas questões ${ }^{4}$ :

- Que questões levantam os recentes protestos globais de ocupação das praças, em termos de pensamento do espaço da cidade e do seu uso (distribuição de espaço público / espaço privado / espaços comuns / espaços restritos)? 


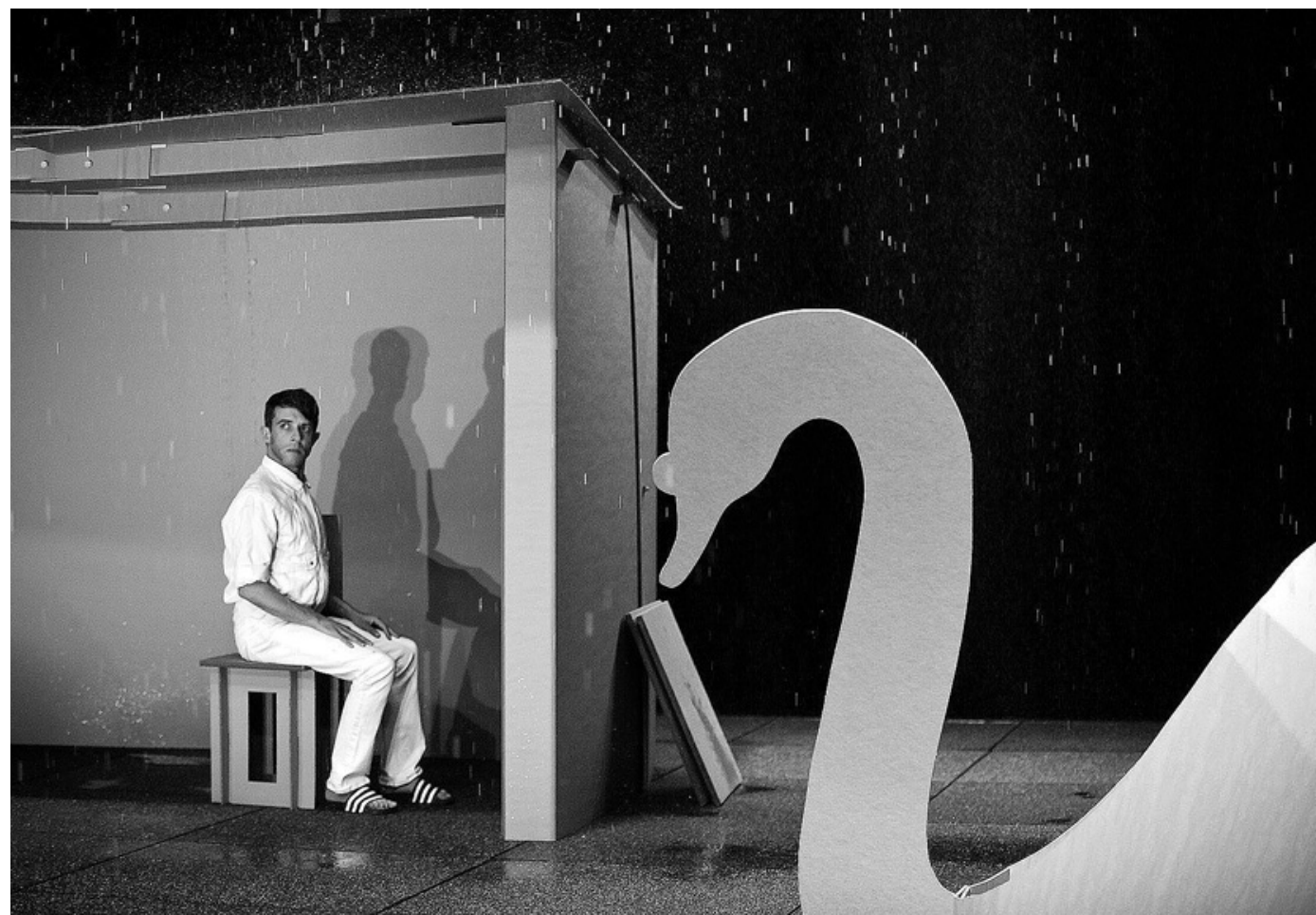

Blessed,

Meg Stuart / Damaged Goods \& EIRA, 2012

(Francisco Camacho)

fot Bylan Douglas.

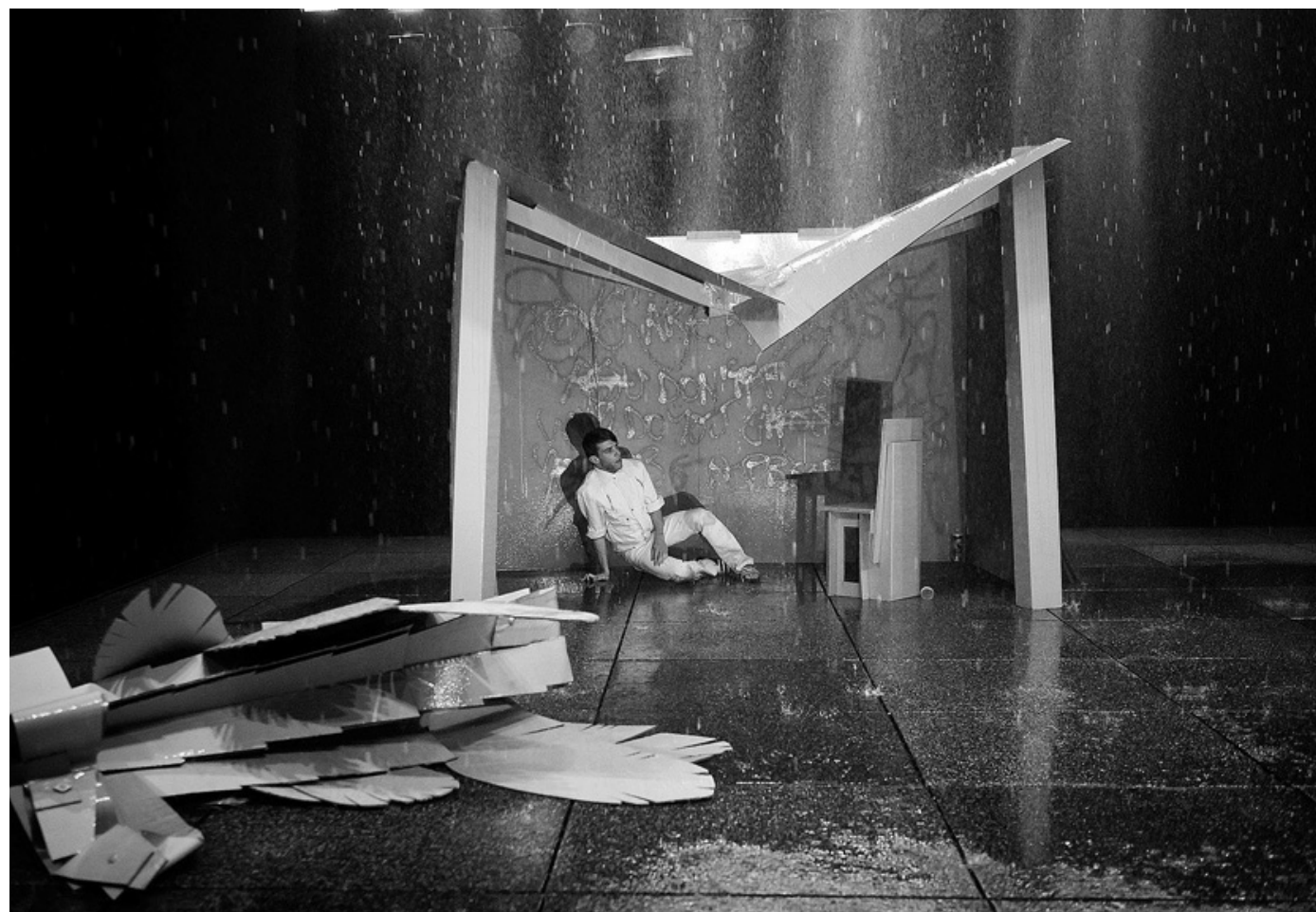

- De que modo estes protestos se relacionam ou diferem de movimentos anteriores, em termos de "repertórios" corporais e uso do espaço da cidade?

- Que características associamos com as posturas, gestos e movimentos dos corpos que vemos nestes protestos?

- De que forma poderão as técnicas de ocupação - que incluem dormir, comer, trabalhar, estudar (ou seja, assegurar a manutenção das condições de reprodutibilidade social no espaço público) - ser entendidas como discurso politico de direito próprio?
- Como encarar estas lutas - feitas com e pelo uso dos corpos juntos no espaço das ruas - na sua relação com a violência omnipresente do corpo policial que circunda os acampamentos e os protestos?

- Que espaços estão a ser contestados e que novos espaços estão a ser criados?

- De que modo é este "estar em pessoa" diferente de "estar em representação", seja de um partido politico, uma agenda pessoal ou um grupo de interesses? 


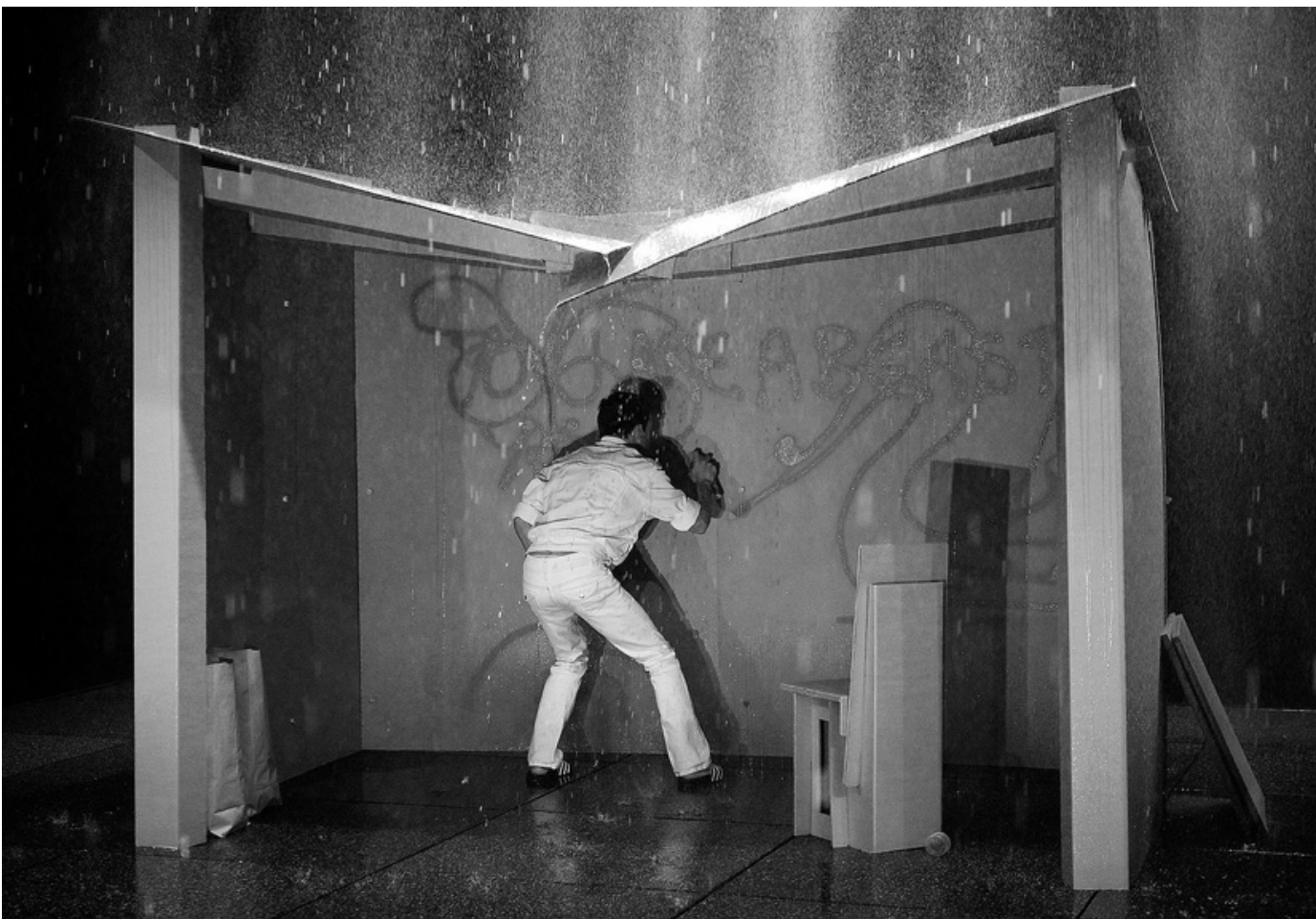

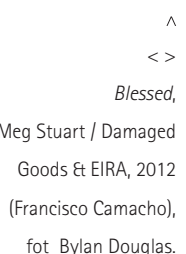

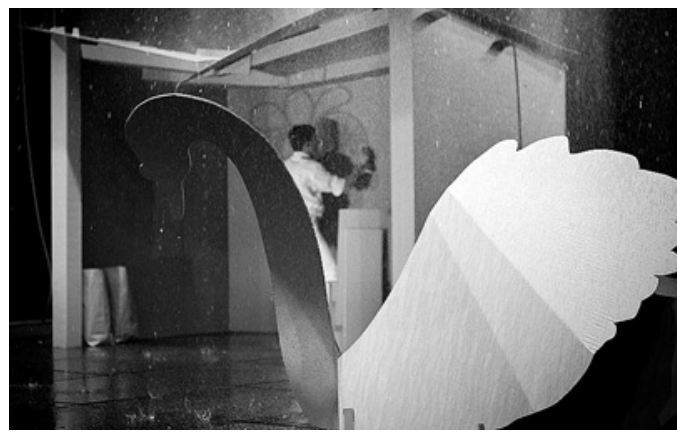

- Pelo que se está a lutar quando se luta pela ocupação destes espaços?

E, de repente, ali, ao ver o espectáculo de Meg Stuart, o mundo que durante uma semana discutimos impôs-seme no palco com toda a violência possivel. Que corpo é este, 0 deste homem exposto assim a esta violência? Que corpos são os nossos quando, igualmente frágeis, vamos para a rua em protesto? 0 que significa usar o corpo em protesto "sem representar"? Como me situo eu (sentada na plateia, longe da chuva, em lugar seguro), espectadora do sofrimento deste homem? Que fazer do desconforto "físico" que Meg Stuart me faz sentir? Devo partilhá-lo, ir também eu para a chuva, e trazê-lo para o campo de visibilidade do mundo: serão isso os acampamentos?

Este homem, sei-o, não tem aparentemente saída, não tem como sair daquela situação, afastar-se da chuva (e não parece ser assim com a dívida, com as desigualdades, com.?) 0 que é reforçado pelo aparecimento momentâneo da figura muito agressiva de uma mulher asiática (em estilo David Lynch / Las Vegas) que, ironia das ironias, se pode deslocar onde não chove. E pela intrusão de um outro agente exterior (Abraham Hurtado) que depois da 'catástrofe' o veste, mas nem por isso o protege ou o tira dela (e não são assim as organizações humanitárias, e a estafada

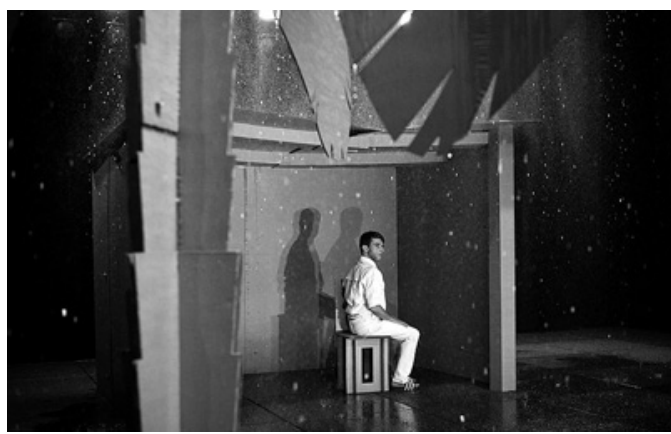

retórica do humanismo, que nunca chega para todos?).

Em Blessed um dispositivo mínimo, fazendo deslocar as condições da rua para o palco e acelerando o tempo

(afinal o que aqui vemos não é assim tão diferente do semabrigo que, nesta noite de menos 3 graus celcius, está à porta do teatro...), torna-nos espectadores de uma violência máxima.

Uma violência que sentimos acumular-se fisicamente em nós enquanto testemunhamos a chuva a cair em cima do corpo (e do mundo) do homenzinho esquisito que nos aparece em palco.

Foi assim, encolhida e a pensar no mundo em que vivemos, ainda meio em choque ${ }^{5}$, que saí de Blessed de Meg Stuart. Um espectáculo que tem o condão de, como os acampamentos de protesto, trazer para o campo de visibilidade do mundo questões tão básicas como a partilha de um novo quotidiano, o direito a comida, à habitação, à educação, a uma vida em "comum" - um "comum" ainda em invenção.

\section{Referência bibliográfica}

LEPECKI, André (2010), "Zones of Resonance", Move. Choreographing you. Art and Dance Since the 1960, in Stephanie Rosenthal (org), Hayward Gallery, London, 2010 